\title{
Loan servicers' incentives and optimal CDOs
}

\author{
Henri Pagès* \\ Banque de France, Research Department
}

April 2, 2010

\begin{abstract}
The paper examines a delegated monitoring problem between investors and a servicer managing a pool of securitized loans subject to Markovian "contagion." Moral hazard induces a foreclosure bias in the decision of the loan servicer unless she is compensated with the right incentive-compatible contract. The asset pool is liquidated when losses exceed a state-contingent cut-off rule. The servicer bears a relatively high share of the risk initially, as she should have high-powered incentives to renegotiate, but her long term financial stake tapers off as losses unfold. Liquidity regulation based on tranching can replicate the optimal contract. The sponsor provides an internal credit enhancement out of the proceeds of the sale and extends protection in the form of weighted tranches of collateralized debt obligations (CDOs). In compensation the trust rewards the servicer with servicing and rent-preserving fees for outcomes that signal diligent servicing, i.e., if a long enough period elapses with no losses occurring. Rather than being detrimental, well-designed securitization seems an effective means of implementing the second best.
\end{abstract}

Keywords: Credit risk transfer, Securitization, Default Risk, Servicer, Contagion

JEL classification: G21, G28, G32

*Banque de France, DGEI, 49-1431, E-mail address: henri.pages@banque-france.fr. I thank Viral Acharya, Diana Bonfim, Ricardo Caballero, Gilles Chemla, Gabriella Chiesa, Monique Jeanblanc, Esa Jokivuolle, Guy Laroque, Antoine Martin, Romain Rancière for helpful discussions, as well as participants in seminars at Bank of France, TSE, Bank of Finland, CREST, IMF, MIT-WEL 2009, Évry, PSE, Bachelier, $2^{\text {nd }}$ PWRI Workshop in Toulouse, the CREDIT 2009 conference in Venice, AFBC 2009 conference in Sydney and $3^{\text {rd }}$ EIF International Forum in Paris for useful comments. I am especially indebted to Bruno Biais and Jean-Charles Rochet for pointing out a flaw in the previous version and making invaluable suggestions for improvement. All errors are mine. The usual disclaimer applies. 


\section{Introduction}

The unprecedented tide of foreclosures that swept through the subprime mortgage market in 2007 has shifted the attention of policymakers to the crucial decisions of loan servicers operating under securitization agreements. Failure to commit adequate loss-mitigation techniques can result in significant foreclosure biases in securitized subprime mortgage, especially when delinquency rates are high, with an economically meaningful impact on credit performance. This buy-side agency problem can be felt acutely if the rise in foreclosures creates negative externalities on housing prices that exacerbate default risk and ultimately jeopardize financial stability. The purpose of the paper is to study optimal compensation in servicing, knowing that servicers exert unobservable effort to control losses arising from a given pool and that imperfect correlation between defaults generates tail risk in the loss distribution.

While weak underwriting standards have arguably played a leading role $^{1}$ in the subprime-mortgage financial crisis, servicing decisions have also attracted much attention ${ }^{2}$ in the recent literature. A relevant concern is whether contractual frictions in the securitization process can prevent servicers from efficiently assisting troubled borrowers under adverse macro shocks. When the outstanding balance on mortgages exceeds homes' current market value, foreclosures are inefficient because they impose deadweight costs that could be avoided through debt forgiveness or loan renegotiation. The anticipation of foreclosures also weakens incentives to conduct adequate maintainance of the property as well as keep tax and insurance bills current, thus exposing servicers to moral hazard on the part of homeowners. This is probably one of the reasons why public policy has attempted to reduce foreclosures by offering subsidies to mortgage servicers who carry out mass modifications, as illustrated by the recent "Homeowner Affordability and Stability Plan" in the US.

The notion that servicer quality has a significant impact on the realized level of losses is consistent with the increasing realization laid out in the Federal Register (2005) that the role of servicers in asset-backed securities (ABS) transactions is as important to the performance of the pool as its initial composition and characteristics. To shed light on this moral hazard problem in the time dimension, we start with a stylized

\footnotetext{
${ }^{1}$ See for instance IMF (2008), Dell'Ariccia et al (2008), Demyanyk and Van Hemert (2009), O'Keefe (2009).

${ }^{2}$ Pennington-Cross and Ho (2006), Ashcraft and Schuermann (2008), Piskorski et al (2009), Adelino et al (2009), Foote et al (2009), Mulligan (2009).
} 
model where the servicer may engage in unobservable actions that result in private benefits at the expense of performance. More specifically, the servicer can make a costly effort at any point in time to service diligently, in which case the loss intensity of the pool is less than what woud have prevailed otherwise at that time. We assume that only diligent servicing is viable. Given competitive investors, the goal is to elicit which high-powered compensation maximizes the servicer's payoff subject to a zero-profit condition for investors and an incentive compatibility condition for servicing.

The setting is closely related to the continuous-time principal-agent model with large and infrequent risks studied by Biais et al (2009), with the twist that (i) ABS refer to a discrete pool of assets that eventually ceases to exist, implying that the solution is non-stationary, and (ii) defaults are assumed to be imperfectly correlated according to a Markovian view of "contagion," where the underlying (conditional) intensity of loss cannot decrease with the arrival of default. Laurent et al (2008) argue that such a reduced-form approach is well-suited to capture the dependence structure generated by a one-factor Gaussian copula or a typical base correlation curve for the iTraxx. Contagion arises from the fact that individual risk is not idiosyncratic. Each default creates an externality on market participants' views about the quality of the rest of the portfolio. The smaller the size of the portfolio, the higher the individual risk.

The contribution of the paper is twofold. First, we characterize the optimal credit risk transfer (CRT) policy for a static pool of identical, long-term defaultable loans with constant cash flows per unit time and liquidation value of zero. The policy relies on two instruments: positive payments to the servicer and the threat of stochastic liquidation. In line with the growing literature on dynamic moral hazard, these decisions are made on the basis of two state variables: the size of the portfolio and the continuation utility of the servicer. While the former reflects the total number of losses, the latter summarizes the track record of performance. The two must be distinguished because the assessment of performance relies on how quickly the portfolio has unraveled, not how much.

Consider first the compensation policy. In order to have the servicer work in their best interest, investors resort to the carrot-and-stick approach. The former is rewarded by the latter only when the track record is on target. Two kind of fees are paid in the "bliss" state. One is the direct servicing fee which is a flat 
percentage of the outstanding loan balance. The other is a rent-preserving fee for impatience which depends on the servicer's discount rate. When the track record deteriorates, however, payments are suspended. The servicer takes stick from investors through a reduction in her continuation utility when a loss occurs. The magnitude of the "penalty" is pinned down by the incentive compatibility constraint. In the beginning underlying risk is low and it is difficult to disentangle a diligent servicer from a careless one. She needs high-powered incentives and bears the brunt of initial losses. In the end underlying risk is high and the likelihood of subsequent defaults makes the servicer eager to apply her best collecting skills. She is shielded in part against the incidence of losses in financial distress. Thus, the servicer's risk share tapers off as losses unfold, until the pool is liquidated.

Consider next the stochastic liquidation policy. Penalties meted out after losses define the servicer's reservation utility. When continuation utility comes close to reservation level, the threat of reductions has no real bite because the servicer is protected by limited liability. To cope with the situation, investors allow for random liquidation ${ }^{3}$ of the pool at the time of default, with a probability of survival reflecting the current performance. The threat of liquidation impels the servicer to remain diligent when performance is poor but is socially costly, so investors are keen to keep stochastic liquidation as far as possible from target. The gap between the best and worst performances for given size defines a contingent cut-off rule. It is the highest permissible level for losses starting from bliss or, more precisely, the maximum number of joint defaults that a high-performing servicer is allowed to make without fearing liquidation. It plays exactly the same role as the continuation threshold in Holmstrom and Tirole (1998), except for the contingency on size, and can as well be interpreted as the outcome of second-best risk-sharing. Tuning the cut-off rule is as effective an instrument to discipline the servicer as the punishment itself.

The second contribution of the paper is about the implementation of optimal CRT under the benchmark of "lumpy" adjustments in individual risk from junior to senior tranches. We show that optimal compensation can be achieved through securitization with true sale. The trust actually buys the pool of loans and asks the

\footnotetext{
${ }^{3}$ An alternative threat against a non-performing servicer would be downsizing the portfolio. Although this would achieve essentially the same outcome, the implementation might be more difficult if loans are indistinguishable. Recurrent downsizing could also be viewed as more disruptive.
} 
sponsor to post the required capital and gains on sale into a liquidity buffer which serves two functions. One is to provide collateral for protection underwritten by the the sponsor on behalf of the servicer in the form of a portfolio of CDOs which match the desired penalties. The other is to tie compensation to servicer's performance, with payments made to the sponsor when the current balance is on target and suspended otherwise. Both the (limited) insurance function and the market-based pricing function are underscored by the liquidity management of the trust, whose role is to maintain the balance between prescribed sizedependent caps and floors.

Such a credit enhancement mechanism based on a proper allocation of CDOs subordinates the cash flows to overall performance, without prejudice of the fees which remain at the top of the flow of funds. It is explicit, rather than based on back-up credit lines or other forms of implicit support which overwhelm bank liquidity in crisis times. It relies on loss intensities that can be calibrated from market imputs such as CDO tranche premiums at the time of issuance. It is prefunded with the proceeds of the sale. Finally, it is subject to a regulatory charge, as the $\mathrm{CDO}$ premiums are retained by the trust, and resembles capital insurance in that liquidity provision by the trust is triggered under circumstances that can only arise as a result of contagious losses. From the implementation scheme, a relevant toehold for strengthening regulation suggests itself in terms of securitization, liquidity and transparency when contractual frictions between investors and servicers are the main issue.

The paper is organized as follows. In Section 2, we present the model and characterize the optimal contract under the incentive compatibility and limited liability constraints. Based on this analysis, Section 3 adopts a backward recursive approach to construct the solution of a system of optimal control problems and derive the dynamics of pool size. Section 4 deals with implementation issues and highlights possible reasons why the optimal scheme is not seen in practice. Section 5 relates the paper with the literature before the conclusion in Section 6. An Appendix contains details about the analytics of pool size and the proof of Proposition 3. 


\section{The model}

Monitoring is often viewed as the choice of costly effort made by a lender at origination to screen borrowers in an adverse selection environment. In this paper, we emphasize instead the choice of costly effort dedicated by one or more servicers during the life of the loans to support a deteriorating performance. The Federal Register (2005) shows that servicing is often quite complex in securitization and can entail a division of responsibilities between several entities: a "master servicer" oversees the action of other servicers, "primary servicers" are responsible for primary contact with obligors and collection efforts, "special servicers" are charged with handling borrower work-out and foreclosure functions, while an "administrator" is entrusted with the dynamic management, possibly adding units to the pool from funds set aside or recycled cash flows.

Such continuous servicing has two consequences. First, the distinction between the exogenous base quality of the loans and the endogenous default probability that obtains after the servicing decision has taken place arises at each point in time. Second, the cost of servicing depends on how defaults propagate in the portfolio. We rely on a homogeneous "contagion" Markov model where the loss intensity of the $n$ th-todefault loan depends on the size of the pool. We show that, if investors can commit, they will ensure that servicers are diligent by subordinating fees to performance and winding down the pool when losses exceed a state-dependent threshold.

\subsection{Continuous servicing}

Consider a pool of securitized loans held by a trust on behalf of investors and administered by a servicer. The former have unlimited liability and supply liquidity competitively, as long as they cover the costs. The latter is the sole entity which borrowers interact with and is affiliated with a sponsor which has funds to invest. There is universal risk neutrality and the servicer is more impatient than investors. Investors' objective is to find a contract that maximizes their expected profit subject to the servicer's reservation utility. Knowing this, the sponsor will offer investors a contract that fetches as much as possible and lets investors break even.

The pool consists of $I$ unit loans, the default risk of which has some systematic component. All loans are ex ante identical and yield $\mu$ per unit time. The pool is static, with no reinvestment after time zero. However, 
when a loan gets repaid, it is immediately replaced by a loan with the same characteristics. Investors can commit to liquidate the pool in case of poor performance, but loans are worth nothing if not managed by the servicer. This is meant to capture the idea that pool illiquidity stems in large part from the servicer-borrower relationship, implying that the ability to collect loans rests squarely on her unique skills at working with borrowers behind on payments and extracting more concessions from them.

Let $i=I-N_{t}$ be the size of the pool ${ }^{4}$ at time $t$, where $N_{t}=0, \ldots, I$ is the default count. Downsizing occurs either as a result of individual defaults or of liquidation by investors. The information $\mathcal{F}_{t}$ is the natural filtration associated with default and liquidation. The default count $N_{t}$ is a controlled time-homogeneous and Markovian process (Karlin and Taylor, 1975). Under the risk neutral probability, the individual default indicators $N_{t}^{j}$ have default intensities depending on the size of the pool and on the quality of servicing. If the servicer is diligent, default intensities are $\alpha^{j}(t)=\alpha_{i}$ for the $i$ loans still outstanding and zero for the loans already terminated. Thus, as long as the pool is spared from liquidation risk, the aggregate loss intensity is $\lambda_{i}=\sum_{j} \alpha^{j}(t)=i \alpha_{i}$

Servicing is costly and unobservable to investors. It affects risk only at the time it is exerted. As in Holmström and Tirole (1998) there are two levels of effort. If the servicer chooses to shirk $\left(e_{t}=0\right)$, she enjoys a private benefit $B d t$ per loan between $t$ and $t+d t$, in which case the aggregate loss intensity, $(1+\epsilon) \lambda_{i}$, is higher than what it would be under monitoring $\left(e_{t}=1\right)$, uniformy in $i$. One interpretation of $\epsilon \lambda_{i}$ is the foreclosure bias obtained when servicers apply their best loss-mitigation techniques to delinquent loans.

A contract specifies the amount $\delta_{t}$ to be paid to the servicer and the time $\tau$ at which liquidation occurs, if ever. Liquidation is unpredictable and stochastic, as it takes place only after a loss and depends on the realization of a lottery. The survival probability given default is denoted by $\theta$, so the pre-liquidation intensity associated with the indicator $M_{t}=1_{\{t \geq \tau\}}$ is $\lambda_{i}\left(1+\left(1-e_{t}\right) \epsilon\right)(1-\theta)$. The sequence of events is as follows. The size inherited from the past is $i$. The servicer receives payment $\delta_{t} d t$ and makes effort decision $e_{t}$ for $(t, t+d t)$. With probability $\lambda_{i}\left(1+\left(1-e_{t}\right) \epsilon\right) d t$ there is a loss and the size becomes $i-1$. Then the pool is liquidated with probability $1-\theta$. Otherwise the servicer keeps administering the pool, with initial size or

\footnotetext{
${ }^{4}$ To avoid cumbersome notation, the time index of portfolio size $i$ is systematically suppressed.
} 
one less unit. We make the following assumptions.

Assumption 1 Only diligent servicing is viable

$$
\frac{\mu+B}{\alpha_{i}(1+\epsilon)}<1<\frac{\mu}{\alpha_{i}}, \quad \text { for all } i
$$

Loans have positive net present value only under diligent servicing. Equivalently, the opportunity cost of servicing poorly - the foreclosure bias $\epsilon \alpha_{i}$ net of private benefits $B$ - is greater than the net return $\mu-\alpha_{i}$. Hence $e_{t}=1$ is optimal throughout. The condition also implies that the servicer's rent under size $i$, $b_{i}=B /\left(\epsilon \alpha_{i}\right)$, is bounded above by $B /\left(B+\mu-\alpha_{i}\right)<1$.

Assumption 2 The sequence $\alpha_{i}$ is decreasing: $\alpha_{i} \leq \alpha_{i-1}$ and $\inf _{i \geq 2} \lambda_{i}>r$.

As shown in the calibration of intensities by Laurent et al (2008), with positively correlated default times the underlying loss intensity cannot decrease with the arrival of new defaults. Markovian contagion between defaults can be introduced by assuming that the sequence $\alpha_{i}$ is low in the beginning and eventually high, i.e., $\alpha_{I} \leq \alpha_{I-1} \leq \cdots \leq \alpha_{1}$. This imperfect correlation between default times undermines the servicer's ability to diversify credit risk and makes the last few loans comparable to "economic catastrophe bonds" (Coval et al, 2009), low in risk unconditionnally but likely to be wiped out if the risk materializes.

\subsection{Incentive compatibility and limited liability}

Let $r$ be the servicer's rate of impatience. The interest rate, including any premium that investors pay for consuming early, is normalized to zero. As in Sannikov (2008) or Biais et al (2009), we specify the servicer's lifetime utility at $t$ as the conditional expected discounted revenue of her activities

$$
U_{t}=E\left[\int_{0}^{\tau} e^{-r s}\left(\delta_{s}+\left(1-e_{s}\right) B\left(I-N_{s}\right)\right) d s \mid \mathcal{F}_{t}\right],
$$


given a contract $(\delta, \tau)$ and an effort process $e$. Related to lifetime utility is continuation utility defined as

$$
u_{t}=1_{\{t \leq \tau\}} E\left[\int_{t}^{\tau} e^{-r(s-t)}\left(\delta_{s}+\left(1-e_{s}\right) B\left(I-N_{s}\right)\right) d s \mid \mathcal{F}_{t}\right]
$$

The servicer participates only if her continuation gains, plus any monetary and private dividends, match her impatience. Since

$$
U_{t}=\int_{0}^{t \wedge \tau} e^{-r s}\left(\delta_{s}+\left(1-e_{s}\right) B\left(I-N_{s}\right)\right) d s+e^{-r t} u_{t}
$$

is a martingale, the integral representation theorem for point processes (Brémaud, 1981) implies that there are predictable processes ${ }^{5} h^{1}$ and $h^{2}$ such that the continuation utility satisfies the promise-keeping equation

$$
\begin{array}{r}
d u_{t}+\left(\delta_{t}+\left(1-e_{t}\right) B\left(I-N_{t}\right)\right) d t=r u_{t} d t-h_{t}^{1}\left(\sum_{j} d N_{t}^{j}-\alpha_{t}^{j}\left(1+\left(1-e_{t}\right) \epsilon\right) d t\right) \\
-h_{t}^{2}\left(d M_{t}-(1-\theta) \lambda_{i}\left(1+\left(1-e_{t}\right) \epsilon\right) d t\right)
\end{array}
$$

until liquidation. The expected change in continuation utility, net of payments and private benefits, is equal to $r$, while $h^{1}$ and $h^{2}$ are the sensitivities of utility to individual losses and liquidation, respectively. We have the following result, in line with Sannikov (2008, Proposition 2).

Proposition 1 Given a contract $(\delta, \tau)$, choosing $e_{t}=1$ is incentive compatible if and only if

$$
h_{t}^{1}+(1-\theta) h_{t}^{2} \geq b_{i}=\frac{B}{\epsilon \alpha_{i}}
$$

almost surely for all $t \in[0, \tau]$.

Heuristically, if the servicer plans to follow the optimal strategy $e=1$ starting from $t$, she should have no incentive to deviate before $t$. From (1), her continuation utility $u_{t}$ is determined by the history of defaults and the contract $(\delta, \tau)$ after time $t$, not by effort before time $t$. Given $u_{t}$, she will not deviate between $t-d t$ and $t$ if the real change in continuous utility $d u_{t}-r u_{t} d t$ is lower under diligent servicing. This

\footnotetext{
${ }^{5}$ Since oustanding loans are indistinguishable, we assume w.l.o.g. that $h^{1}$ is a scalar process.
} 
yields the incentive compatibility constraint (3). The left-hand side is the "penalty," the predictable loss in utility brought about by default or liquidation risk. The right-hand side is the minimum rent consistent with diligent servicing in state $i$, the usual non-pledgeable income reflecting the attractiveness of private benefits when the agent is shirking. It defines reservation utility, since below $b_{i}$ utility would be less than the penalty imposed after a loss.

A high sensitivity to losses requires that the servicer be compensated with high utility in the begining. This reduces investors' value. Hence, the incentive compatibility binds under the optimal plan. Because liquidation is inefficient and should be avoided to the extent possible, there are two regimes for the servicer. Either $u \geq b_{i}+b_{i-1}$ and there is no need to liquidate the pool $(\theta=1)$. The loss in utility is $h_{t}^{1}=b_{i}$ and since $u-b_{i} \geq b_{i-1}$ the limited liability constraint is not violated in state $i-1$. Or $b_{i} \leq u<b_{i}+b_{i-1}$ and liquidation is necessary. Since all is lost when the pool is liquidated, the promise-keeping constraint yields $u=h^{1}+h^{2}$. The incentive compatibility constraint in turn determines $\theta=\left(u-b_{i}\right) /\left(u-h_{1}\right)$. But limited liability has $u-h^{1} \geq b_{i-1}$ when the pool is spared, so $\theta$ is maximized when $h^{1}=u-b_{i-1}$ and $h^{2}=b_{i-1}$. The optimal survival probability, $\theta=\left(u-b_{i}\right) / b_{i-1}$, reflects the servicer's position in the interval $\left[b_{i}, b_{i}+b_{i-1}\right]$. If a default occurs, utility is first reduced to $u-h^{1}=b_{i-1}$, the servicer's reservation utility in state $i-1$. Then a loaded coin (probability $\theta$ ) is thrown. Heads the servicer remains in charge and her utility starts growing. Tails the pool is liquidated and $b_{i-1}-h^{2}=0$.

\subsection{Optimal contracting}

If $h^{1}=b_{i} \wedge\left(u-b_{i-1}\right), h^{2}=b_{i-1}$ and $\theta=\left(\left(u-b_{i}\right) / b_{i-1}\right) \wedge 1$, the contract is incentive compatible. The promise-keeping equation (2) returns

$$
\begin{aligned}
\dot{u}(t)+\delta_{t} & =r u(t)+\lambda_{i} b_{i} \wedge\left(u(t)-b_{i-1}\right)+\lambda_{i}(1-\theta) b_{i-1} \\
& =r u(t)+\lambda_{i} b_{i}
\end{aligned}
$$


between two successive losses. The servicer charges two kinds of fees to investors. One shields her against the incidence of losses for which she is not accountable under diligent servicing. The servicing fee $\lambda_{i} b_{i}=i B / \epsilon$ is a flat percentage of the outstanding pool. The other maintains the real value of her continuation utility and is tuned to the rate of impatience.

In this time-homogeneous setup, as usual in models of dynamic moral hazard, the current size of the pool $i$ and the servicer's current utility $u$ are sufficient statistics for the optimal contract. Investors' continuation utility, $v_{i}(u)$, satisfies the following system of Hamilton Jacobi Bellman equations which can be solved recursively from $i=1$ to $I$

$$
\max _{\delta_{t}(\cdot)}\left\{\left(r u+\lambda_{i} b_{i}-\delta_{t}\right) \dot{v}_{i}(u)+i \mu-\delta_{t}-\lambda_{i} \theta\left(v_{i}(u)-v_{i-1}\left(\left(u-b_{i}\right) \vee b_{i-1}\right)-\lambda_{i}(1-\theta) v_{i}(u)\right\}=0,\right.
$$

where $\theta=\left[\left(u-b_{i}\right) / b_{i-1}\right] \wedge 1$ is the optimal probability of liquidation given default and $v_{0}(u)=0$. The first term is the change in continuation value brought about by the drift in $u$. The second is the revenue from the loans net of payment to the servicer. The last two correspond to the loss of utility incurred depending on whether the servicer keeps operating or not, respectively. With the extrapolation $v_{i}(u)=\left(u / b_{i}\right) v\left(b_{i}\right)$ on $u \in\left[0, b_{i}\right]$ the HJB equations can be simplified as

$$
\max _{\delta_{t}(\cdot)}\left\{\left(r u+\lambda_{i} b_{i}-\delta_{t}\right) \dot{v}_{i}(u)+i \mu-\delta_{t}-\lambda_{i}\left(v_{i}(u)-\theta v_{i-1}\left(u-b_{i}\right)\right)\right\}=0
$$

Movements in $u$ reflect the history of individual losses: $u$ keeps increasing towards some target unless some unexpected default brings it down. The complementary slackness condition $\delta_{t}\left(\dot{v}_{i}(u)+1\right)=0$ helps explain why. When $u$ is above target, social surplus $u+v_{i}(u)$ is maximized and $\dot{v}_{i}(u)=-1$. Investors prevent $u$ from rising above target by paying fees to the servicer. Below target $\dot{v}_{i}(u)>-1$ and investors are better off postponing payments until the target is reached. A string of unexpected losses can interrupt this process. If $u$ falls below $b_{i}+b_{i-1}$ in state $i$, the servicer fears liquidation risk after a loss. 


\section{Pool size dynamics}

With constant returns to scale, the servicer's reservation utility, $b_{i}=B /\left(\epsilon \alpha_{i}\right)$, does not change as long as $\alpha_{i}$ remains constant. Since $\lambda_{i}=i \alpha_{i}$, the size-adjusted rent $B /\left(\epsilon \lambda_{i}\right)$ edges up as the aggregate foreclosure bias declines with the number of loans outstanding and it becomes increasingly difficult to disentangle a diligent servicer from a careless one. In contrast, when bouts of contagion trigger a sharp rise in underlying default risk, the foreclosure bias rises abruptly. The servicer has less leeway to shirk. We are interested in the implications that such changes have for the design of the optimal contract.

\subsection{Single loan: Constant utility}

Investors set servicer's continuation utility at its minimum level $b_{1}$. This implies a continuous payment of $\delta_{1}=b_{1}\left(r+\lambda_{1}\right)$. In this degenerate special case the HJB equation returns

$$
\bar{v}_{1}=\frac{\mu-\delta_{1}}{\lambda_{1}},
$$

the present value of $\mu-\delta_{1}$ until extinction at time $\tau$ since $E\left[\tau-t \mid \mathcal{F}_{t}\right]=1 / \lambda_{1}$. Optimal policy is captured by the value function $v_{1}(u)=\bar{v}_{1}-\left(u-b_{1}\right)$ for $u \geq b_{1}$. When $u>b_{1}$, an immediate payment of $u-b_{1}$ is made to have the servicer fall back on her reservation utility $b_{1}$. However, $u>b_{1}$ is never reached under the optimal plan.

\subsection{Two loans: Stochastic liquidation}

It no longer pays to limit the servicer to her reservation utility. We know from the incentive compatibility constraint that when $u$ belongs to $\left[b_{2}, b_{2}+b_{1}\right]$, there is stochastic liquidation upon default with rate of survival $\theta=\left(u-b_{2}\right) / b_{1}$. Hence, the servicer's utility can be written as $u=b_{2}+b_{1} \theta$ where $1-\theta$ is the probability that the pool is liquidated if a default occurs. In the absence of payments, her continuation utility grows as

$$
\dot{u}(t)=r u(t)+\lambda_{2} b_{2}=r u(t)+2 B / \epsilon
$$


until $\gamma_{2}=b_{2}+b_{1}$ is reached. It is neither optimal to prevent $u$ from increasing before $\theta$ is equal to one, nor to keep it increasing beyond $\gamma_{2}$. The stochastic liquidation interval is exactly $\left[b_{2}, \gamma_{2}\right]$.

On $\left[b_{2}, \gamma_{2}\right]$ investors' continuation utility $v_{2}(u)$ satisfies the HJB equation

$$
\left(r u+\lambda_{2} b_{2}\right) \dot{v}_{2}(u)+2 \mu-\lambda_{2}\left(v_{2}-\theta \bar{v}_{1}\right)=0
$$

the solution of which ${ }^{6}$ can be written as $v_{2}(u)=b_{1} w_{2}^{1}(\theta)$ for some normalized function $w_{2}^{1}$. The slope at $\theta=1$ is given by the boundary condition $\dot{w}_{2}^{1}(1)=-1$, ensuring that the servicer gets paid only when $u=\gamma_{2}$. Should default of the penultimate loan occur in that state, her utility jumps into the single loan regime $u=b_{1}$.

Investor's continuation utility is concave on $\left[b_{2}, \gamma_{2}\right]$. This property, as in all solutions of higher size, reflects the inefficiency arising from stochastic liquidation. The principal's value reacts all the more strongly to performance as liquidation is likely and the highest inefficiency arises when the servicer is constrained at her reservation level. We assume that a higher performance originally raises investors' continuation utility. A technical condition given in Appendix ensures that this is indeed the case irrespective of the size.

\subsection{Three loans: One exemption from liquidation under probation}

As above, stochastic liquidation arises in the first interval $\left[b_{3}, b_{3}+b_{2}\right]$. Investors' continuation utility can be written as $v_{3}(u)=b_{2} w_{3}^{1}(\theta)$ where the survival probability $\theta=\left(u-b_{3}\right) / b_{2}$ is the position of $u$ in that interval. However, it is no longer optimal to prevent $u$ from exceeding the stochastic liquidation interval. Beyond $b_{3}+b_{2}$ the servicer must be let out on probation for some time. Let $\theta=\left(u_{3}-b_{3}-b_{2}\right) / b_{1}$ be the servicer's position in the second interval $\left[b_{3}+b_{2}, b_{3}+b_{2}+b_{1}\right]$. One can show that investors' utility is now

\footnotetext{
${ }^{6}$ Details of this derivation, as of those in the subsections below, are given in the Appendix.
} 
given by $v_{3}(u)=b_{1} w_{3}^{2}(\theta)$, where the upper boundary of probation $\bar{\theta}_{3}$ solves the two conditions

$$
\begin{aligned}
& \dot{w}_{3}^{2}(\theta)=-1 \\
& \ddot{w}_{3}^{2}(\theta)=0 .
\end{aligned}
$$

The first states that it is no longer cheaper to compensate the servicers using future rewards rather than an immediate transfer. The second is a "smooth pasting" condition ensuring that $\bar{\theta}_{3}$ is optimal: if $w_{3}^{2}$ were strictly concave at $\bar{\theta}_{3}$, more surplus could be obtained by marginally raising the treshold beyond that level. One finds after some substitutions that the critical level $\bar{\theta}_{3}$ lies strictly between 0 and 1 and is such that

$$
1+\dot{v}_{2}\left(b_{2}+\bar{\theta}_{3} b_{1}\right)=\frac{r}{\lambda_{3}}
$$

The penalty is $b_{3}$. If a loss occurs during probation, the servicer sees her continuation utility drop to $u-b_{3}=b_{2}+\theta b_{1}$, so $\theta \in\left[0, \bar{\theta}_{3}\right]$ can be interpreted as the probability of survival given default that the servicer faces when her utility jumps into the two-loan stochastic liquidation interval following a loss. A useful characterization for the sequel is to notice that the servicer is exempted from liquidation once during probation, since two consecutive defaults effectively end the game with strictly positive probability. In the absence of default $u$ keeps increasing until the social value of performance after the penalty is imposed, $1+\dot{v}_{2}\left(u-b_{3}\right)$, equates its cost $r / \lambda_{3}$ at $\theta=\bar{\theta}_{3}$. When $u$ reaches the target $\gamma_{3}=b_{3}+b_{2}+\bar{\theta}_{3} b_{1}$, the slope of investors' continuation utility is -1 and the servicer gets her share in the form of fees.

\subsection{Four loans: Up to two exemptions from liquidation under probation}

With penalty $b_{4}$ stochastic liquidation arises in $\left[b_{4}, b_{4}+b_{3}\right]$. The size of probation depends on a comparison between the current relative cost of performance, $r / \lambda_{4}$, and the social value of performance after the penalty is imposed, $1+\dot{v}_{3}\left(u-b_{4}\right)$. We take cases. 


\subsubsection{Low aggregate loss intensity}

Suppose first that aggregate loss intensity $\lambda_{4}$ is so low that $1+\dot{v}_{3}\left(b_{3}+b_{2}\right) \leq r / \lambda_{4}$. Since $v_{3}$ is strictly concave there exists $\bar{\theta}_{4}$ between 0 and 1 such that

$$
1+\dot{v}_{3}\left(b_{3}+\bar{\theta}_{4} b_{2}\right)=\frac{r}{\lambda_{4}} .
$$

Then probation consists of a single interval $\left[b_{4}+b_{3}, \gamma_{4}\right]$ with target defined as $\gamma_{4}=b_{4}+b_{3}+\bar{\theta}_{4} b_{2}$. If default occurs during probation, servicer's utility drops in the stochastic liquidation interval of $i=3$ with continuation utility $b_{3}+\theta b_{2}$ and associated survival probability $\theta$. In this case there is only one exemption from liquidation following consecutive defaults.

\subsubsection{High aggregate loss intensity}

Suppose in contrast that $1+\dot{v}_{3}\left(b_{3}+b_{2}\right)>r / \lambda_{4}$. Then there exists $\bar{\theta}_{4}$ between 0 and 1 such that

$$
1+\dot{v}_{3}\left(b_{3}+b_{2}+\bar{\theta}_{4} b_{1}\right)=\frac{r}{\lambda_{4}} .
$$

In this case probation consists of two intervals. In the first, $\left[b_{4}+b_{3}, b_{4}+b_{3}+b_{2}\right]$, there is only one exemption from liquidation following consecutive defaults. Should a loss occur the servicer enters stochastic liquidation of $i=3$ with survival probability $\theta=\left(u-b_{4}-b_{3}\right) / b_{2}$. In the second, $\left[b_{4}+b_{3}+b_{2}, \gamma_{4}\right]$ with target defined as $\gamma_{4}=b_{4}+b_{3}+b_{2}+\bar{\theta}_{4} b_{1}$, there are two exemptions from liquidation following consecutive defaults. Investors want the performers in that interval to fall in the probation interval of state 3 , where one more default is allowed without risk of immediate liquidation.

By the concavity of investors' continuation utility $\bar{\theta}_{4}<\bar{\theta}_{3}$ whenever $r>0$. In the advent of default in the bliss state, the servicer falls within probation and does not get payments for some time. The targets 
consistent with the servicer being paid when $i=4$ and $i=3$ are

$$
\begin{aligned}
& \gamma_{4}=b_{4}+b_{3}+b_{2}+\bar{\theta}_{4} b_{1} \\
& \gamma_{3}=b_{3}+b_{2}+\bar{\theta}_{3} b_{1},
\end{aligned}
$$

respectively. Since $b_{4} \geq b_{3} \geq b_{2} \geq b_{1}$, the size-adjusted gap is minimized when all $b_{i}$ are equal, $\bar{\theta}_{4}=0$ and $\bar{\theta}_{3}=1$, yielding

$$
\frac{\gamma_{4}}{4}-\frac{\gamma_{3}}{3} \geq b_{4}\left(\frac{1}{4}-\frac{1}{12}-\frac{1}{12}-\frac{1}{12}\right)=0
$$

The servicer loses from the bliss state of $i=4$ to that of $i=3$, not only in absolute terms, but also in relative terms.

The intuition behind these two cases is the following. Aggregate loss intensity is maximal for $i=4$ when "contagion" has spread with the highest possible individual risk $\left(\alpha_{4}=\alpha_{3}\right)$. Looking forward, the servicer's size-adjusted reservation rent grows by $33 \%$ following default $\left(b_{3} / 3=4 / 3 b_{4} / 4\right)$. This creates risk shifting incentives when performance is poor. To mitigate those risks when $i=4$, investors design probation with two intervals, meant to be reduced to a single one when $i=3$. As shown above, the size-adjusted target, and consequently the payment made, are higher. So the size-adjusted reservation rent is improved but the size-adjusted reward received under bliss also curtailed in the advent of default.

If on the contrary delinquencies are not likely when there are four loans $\left(\alpha_{4} \ll \alpha_{3}\right)$, the servicer enjoys a high rent in that state and is undermined by the downsizing. There is no need to shrink probation going forward. With only one exemption from liquidation, the servicer has to wangle her way into both the stochastic liquidation and probation intervals of $i=3$ in the advent of default. In this still rather special case it is not possible to shrink probation below a single interval since it would otherwise be empty. This need not be the case for higher order states with a large number of probation intervals. Thus looking forward, contraction is by one interval at most, but expansion can be sizable. The punchline is that, looking forward, the cost of performance $r / \lambda$ rises slowly during spells of constant individual risk and small cuts in the number of exemptions from liquidation hold the servicer's rent in check. In contrast, the cost of performance shrinks 
following a sharp worsening of credit risk and lump increases in the number of exemptions help restore incentives to service diligently.

\subsection{General case}

We can now state the following.

Proposition 2 Under Assumptions 1 to 3, the solution of the HJB system of equations

$$
\begin{aligned}
\max _{\delta_{t} \cdot(\cdot) \geq 0} & \left\{\left(r u+\lambda_{i} b_{i}-\delta_{t}\right) \dot{v}_{i}(u)+i \mu-\delta_{t}-\lambda_{i}\left(v_{i}(u)-\theta v_{i-1}\left(u-b_{i}\right)\right)\right\}=0 \\
\text { s.t. } \quad d u+\delta_{t} d t= & r u d t-\left(b_{i} \wedge\left(u-b_{i-1}\right)\right)\left(\sum d N_{t}^{i}-\lambda_{i} d t\right)-b_{i-1}\left(d M_{t}-(1-\theta) \lambda_{i} d t\right) \\
\theta & =\frac{u-b_{i}}{b_{i-1}} \wedge 1
\end{aligned}
$$

has maximal solutions $v_{i}(u)$ over $\left[b_{i}, \infty\right)$. The functions $v_{i}$ are globally concave, continuously differentiable, with first positive slope and eventually slope -1 over $\left[\gamma_{i}, \infty\right)$, where

$$
\gamma_{i}=\sum_{j=0}^{l(i)} b_{i-j}+\bar{\theta}_{i} b_{i-l(i)-1}, \quad \bar{\theta}_{i} \in[0,1]
$$

is the target rent in state $i$. On $\left[b_{i}, b_{i}+b_{i-1}\right)$ there is stochastic liquidation given default with probability $1-\theta$. On $\left[b_{i}, \gamma_{i}\right)$ payment is differed. The cut-off rule $l(i)$ satisfies $l(i+1) \leq l(i)+1$, with $l(1)=l(2)=0$ and $l(3)=1$. The scale $\bar{\theta}_{i}$ is the probability of survival after $l(i)+1$ joint defaults in the bliss state, with $\bar{\theta}_{i+1} \leq \bar{\theta}_{i}$ if $l(i+1)=l(i)+1$ (strict inequality if $r>0$ ) and $\bar{\theta}_{1}=0, \bar{\theta}_{2}=1$. The cut-off rule and scale $\left(l(i), \bar{\theta}_{i}\right)$ are uniquely determined by the recursive conditions

$$
1+\dot{v}_{i}\left(\sum_{j=1}^{l(i)} b_{i-j}+\bar{\theta}_{i} b_{i-l(i)-1}\right)=\frac{r}{\lambda_{i}} .
$$

In particular $l(i)=i-2$ and $\bar{\theta}_{i}=1$ if $r=0$. 
The optimal risk transfer policy relies on two instruments: the prospect of future payments if there is no loss for some time (the carrot), and the risk of stochastic liquidation if there is a spell of poor performance (the stick). This history dependence is summarized by two variables: past downsizing, reflected in the number of loans outstanding $i=I-N$, and past performance, reflected in the servicer's informational rent $u$. The minimum rent consistent with diligent servicing is $b_{i}$. Given track record $u \geq b_{i}$, it makes sense for investors to encourage the servicer to improve her credentials before making payments. To keep her participating, they let the rent grow at a rate consistent with pool size and rate of impatience. Proposition 2 determines how far the target $\gamma_{i}$ is away from $b_{i}$. Once the target is reached, the servicer is paid.

Suppose there are $i$ loans outstanding, ordered by the rank in which they default, i.e., number $i$ is the first to default, $i-1$ the next and so on. (It does not matter which particular loans are chosen, since they are identical.) The bottom rent $b_{i}$ is associated with a $100 \%$ probability of liquidation given default $(\theta=0)$. Suppose instead investors depart from the stochastic liquidation rule and commit not to liquidate the pool if loan $i$ defaults. Incentive compatibility requires $u_{i}-b_{i} \geq u_{i-1}$ so $b_{i}+b_{i-1}$ is the minimum rent consistent with one exemption from liquidation $(l(i)=1)$. Likewise, if investors commit to exempt the pool from liquidation for up to $l(i)$ consecutive defaults, the servicer's rent immediately jumps to $\sum_{j=0}^{l(i)} b_{i-j}$. Hence $l(i)$ can be interpreted as the cut-off rule associated with state $i$. It is the maximum number of joint defaults that the servicer can withstand without fearing liquidation under the best track record.

Under the optimal plan the level of commitment is contingent on the servicer's past performance. If $u$ is in $\left[b_{i}, b_{i}+b_{i-1}\right]$, commitment is granted with probability $\theta=\left(u-b_{i}\right) / b_{i-1}$. The utility range $\left[b_{i}, \gamma_{i}\right]$ can be broken into $l(i)+1$ "buckets" of weakly decreasing size $b_{i-1}, \ldots, b_{i-l(i)}, b_{i-l(i)-1}$, the last being scaled down by $\bar{\theta}_{i}$. If $u$ happens to be in the $k$ th bucket, $k-1$ exemptions are granted and the $k$ th is reneged with some probability. The process is interrupted when $u$ hits $\gamma_{i}$ and the servicer is paid. In the worst case scenario (which happens with probability zero), $l(i)$ defaults knock the pool in one stroke and servicer's continuation utility collapses to $u=\gamma_{i}-\sum_{j=0}^{l(i)-1} b_{i-j}=b_{i-l(i)}+\bar{\theta}_{i} b_{i-l(i)-1}$. The scale factor $\bar{\theta}_{i}$ is simply the probability of survival faced by the pool following $l(i)+1$ simultaneous defaults in the bliss state. An immediate default for an encore and the pool is liquidated, since $\theta=0$ when $u=b_{i-l(i)-1}$. 
The cut-off rule cannot be decremented by more than one unit looking forward. One special case ${ }^{7}$ arises when $r=0$ and $l(i)=i-2$. Since it makes no sense to defer payments when the servicer is infinitely farsighted, investors lose an instrument and are better off letting the servicer hang on to her target $\sum_{j \leq i} b_{j}$ anyway. There is no risk of private benefit diversion since she enjoys the highest possible rent. This may be very costly. Investors' value can actually be increased by assuming a deterministic cut-off rule. Such rule would trade off the disposal of valuable assets against the saving on servicing costs ex ante. Introducing deterministic liquidation when $r \geq 0$ would not qualitatively change our results, as the recursive solutions would simply start from a prespecified level.

An impatient servicer is given a less ambitious target. To understand the mechanics of the cut-off rule, recall that once on probation the servicer is driven by the prospect of future payments. As long as there are no losses, payments should be resumed soon and the new performance target adjusted to assuage her quest for fees. In normal circumstances - assuming for example individual risk remains constant in a tranche it is not sensible to keep the servicer waiting with the promise of larger payments since underlying conditions have not changed. The reason for actually reducing payments is twofold. First, compensation should not improve in size-adjusted terms and the pool has decayed by one unit. Second, risk shifting incentives should be held in check and foreclosures are slightly less frequent, making shirking more difficult to detect. On both accounts, investors' best reaction is to lower the target by strengthening the cut-off rule. Thus, looking forward from the preceding state, a high-performing servicer knows that size-adjusted fees will be reduced after a loss even if she does not have to wait long and remains diligent.

But there is a twist. Individual risk may surge if the mezzanine or senior tranches of losses are hit. It is then that the servicer's special skills at collecting payments are the most valuable. The aggregate loss intensity soars despite the reduction in pool size and dwarfs the servicer's discount rate, making the cost of performance appear relatively cheap. Investors' best reaction is to rescale the number of permissible losses to take the new conditions into account, i.e., slacken the cut-off rule. By this token, heightened concerns about underlying risk induce an abrupt fall in reservation utility, but their impact on the new target is dampened.

\footnotetext{
${ }^{7}$ The solution obtained by taking limits when $r \rightarrow 0$ is well-defined, with exponentials replacing power functions.
} 
Folding back to the previous state, a high-performing servicer knows that she will have to wait a long time before payments are resumed when operating under turbulence and remains diligent.

\section{Implementation}

For implementation we consider only the relationship between the sponsor/servicer on the one hand and the trust on the other hand, leaving out further aspects concerning securitization, such as consulting with credit agencies or underwriting new securities to outside investors. Affiliated servicers and sponsor are treated on a consolidated basis. We assume that there is no agency problem between them.

Given the history of losses, the optimal contract determines the agent's performance record $u(t)$ as a function of fees $\delta_{t}$ and liquidation policy $\tau$ as

$$
u(t)=1_{\{t \leq \tau\}} E\left[\int_{t}^{\tau} e^{-r(s-t)} \delta_{s} d s \mid \mathcal{F}_{t}\right] .
$$

Using reverse engineering, we can recover optimal fees $\delta$ and liquidation $\tau$ from $u(t)$ through

$$
\begin{aligned}
\delta_{t} & =\left(\frac{i B}{\epsilon}+r \gamma_{i}\right) 1_{\left\{u(t)=\gamma_{i}\right\}} \\
\tau & =\inf \{t: u(t)=0\} .
\end{aligned}
$$

Hence, a natural way to implement the compensation policy is to replicate $u$ dynamically by use of a liquidity buffer that faithfully tracks the implications of losses for the agent's continuation utility. As it turns out, the buffer is continuously managed by the trust and actually plays two roles. One is to provide limited insurance to the market. The buffer is used as collateral for protection underwritten by the sponsor on behalf of the servicer, in a way that reflects how the latter's long-term risk share should evolve as new losses occur. The other is to be the linchpin of performance-based compensation. The current balance reveals outright servicing performance and can be used to tie the amount and timing of fees that must be remitted by the trust to the agent. 
We first determine what share of the securitization project each party is entitled to at inception. The sponsor seeks to maximize profits and, given portfolio size, minimizes the amount of capital needed. Its program at time 0 ,

$$
\begin{array}{lr} 
& \max _{u \geq b_{I}} c u-K \\
\text { s.t. } & K \geq I-v_{I}(u),
\end{array}
$$

shows that, when the constraint binds, social surplus $S=u+v_{I}(u)-I$ is maximized when the nonpledgeable income for the sponsor is set at $u^{*}=\gamma_{I}$ and investors receive the pledgeable part $v^{*}=v_{I}\left(\gamma_{I}\right)$. This of course assumes that the sponsor has enough funds to start with, namely $K=I-v^{*}$. The sponsor then initiates an ABS transaction by selling the pool to a bankruptcy-remote trust with gain on sale $S$ over the principal balance $I$. The trust is willing to pay this premium because the anticipated payments from the arrangement below ensure that it breaks even. The sponsor then credit enhances the deal by returning the share $u^{*}=K+S$ in the form of a liquidity buffer managed by the trust. Finally, it hires a servicer for the pool.

A useful benchmark arises when individual loss intensities are constant in the equity, mezzanine and senior tranches of the pool. Penalties charged after a loss $b_{i}=B /\left(\epsilon \alpha_{i}\right)$ are constant within tranches, so are proportional to the number of defaults in that tranche. But CDOs are based on loan portfolios rather than individual loans, and commit the investor to reimbursing losses within a specific tranche. Hence these penalties can be imposed by requiring servicers to extend protection in the form of a porfolio of CDOs, weighted by $b_{i}$, using the liquidity buffer as collateral (insurance role).

To see this, consider a tranche with attachment points $[L, U]$. It reimburses losses between $L$ and $U$, if any. The protection is $[N-L]^{+}-[N-U]^{+}$, where $U-L$ is the notional size of the tranche. Let $b_{L, U}$ be the common penalty in that tranche. The protection embedded in a portfolio of tranches with "optimal" 
weights adjusted to the underlying penalties,

$$
P(N)=\sum_{[L, U]} b_{L, U}\left([N-L]^{+}-[N-U]^{+}\right),
$$

is just the sum of penalties $b_{j}$ when $j$ runs the gamut from full size $j=I$ to last-to-date size $j=I-N+1$. Thus, the default-contingent exposure $P(N)$ cumulates penalties inflicted on the servicer since the beginning and rises from zero to $\sum_{j=I}^{1} b_{j}$ when the pool is liquidated. Its variation from size $i$ to $i-1$ is driven by the servicer's constant penalties or risk shares $b_{i}<1$ in the tranches. Here the servicer keeps sharing in the risk at a declining rate, until liquidation. This is in marked contrast with standard practice in structured finance, where the common retention mechanism is one for the first-loss piece and zero for all other tranches.

In the model, the optimal retention rate requirement is linked to the incidence of contagion risk. In contrast to the recent amendment of the capital requirement directives, which asks sponsors to keep a minimum "one-size-fits-all" $5 \%$ retention rate in a securitization sold to investors that include a credit institution - in practice a minimum "vertical strip" of each tranche - optimal CRT has declining risk shares. This is consistent with the interpretation put on the information intensity of securities by Gorton and Pennacchi (1990) or Dang et al (2009). Sponsors are better informed about the quality of the pool initially and should hold a significant share of the information-intensive junior tranches. Their share of the ex ante information-insensitive senior tranches should on the other hand be smaller, as they must not take advantage of the privileged information they have if doubts about the quality of borrowers become paramount.

The proposition below suggests that capital requirements alone cannot correct misaligned incentives, but that liquidity regulation may bring them back to the fold. The role of the trust is to pay fees to the sponsor and maintain the buffer balance between size-dependent caps (target) and floors (reservation utility). Fees accrue on the reserve account to increase credit support and are remitted to the servicer only when the balance is on target (market-based compensation). Movements in the reserve account faithfully mirrors pool performance and are used by the trust to trigger stochastic liquidation. 
Proposition 3 With constant individual risk within tranches, optimal CRT can be implemented as follows:

(i) Collateral $u^{*}=K+S$ is withdrawn from the sale and posted in a liquidity buffer managed by the trust;

(ii) The sponsor buys CDO tranches, weighted $b=B /(\epsilon \alpha)$, and waives its rights to the premium spreads;

(iii) The protection embedded in the tranches is assigned to the reserve account;

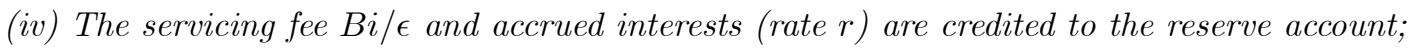

(v) The account balance is maintained between cap $\gamma_{i}$ and floor $b_{i}$ :

- Excess cash triggers payment to the sponsor;

- Overdrafts trigger stochastic liquidation: the trust makes up for the shortfall if the pool is rescued, seizes the account and settles outstanding CDOs if it is liquidated, and breaks even.

Should the balance fall beyond floor, a "regulator" with full commitment is called for and decides whether liquidation is warranted, perhaps on the basis of his superior information. The trust always stands in for the low-performing servicer, either settling the shortfall with a cash payment if the pool is kept afloat, or seizing the account and insulating the buyers of protection from counterparty risk if the pool is liquidated. In exchange for the risk it assumes, the trust retains all CDO premiums as a liquidity tax. Since the arrangement regulates liquidity as in the optimal contract, the sponsor maximizes profits subject to the servicer conducting due diligence on delinquent borrowers and the trust breaks even. The optimal tradeoff between efficient risk sharing and diligent servicing is consistent with separating different functions, with servicers affiliated with the sponsor on the one hand, and parties related to the securitization on the other.

The intuition behind this result is that CDOs are an ideal way to make non-standard and non-traded loans more transparent. The weights of the different tranches reflect the penalty the servicer should face when the corresponding tranches become active. Losses are revealed to dispersed investors as they occur and act as a trigger mechanism to make margin calls. The main difference between margin calls and our mechanism is liquidity management. In a margin account, the broker asks the investor to post new collateral as prices drop. In a reserve account, the cost of the protection is posted in advance and covered by withdrawals as losses unfold. ${ }^{8}$ The margin calls can be determined from the pricing of CDO tranches. Since each CDO is a

\footnotetext{
${ }^{8}$ Relatedly, Hart and Zingales (2008) suggest that the price of CDS should be used to ensure that banks maintain an adequate
} 
"bet" on the portfolio making losses in a specific tranche, their prices reflect the underlying loss intensities as perceived by the market at the time of issuance.

This suggests three reasons might explain why the second-best solution is not observed in practice. One is that after having raised funds and made loans, a bank may not honor its promise to engage in optimal CRT. As pointed out by Chiesa (2008), a sponsoring bank can provide more than the credit enhancement required under the designed policy, holding for example more senior tranches than necessary. Investors break even if this is factored in the sale price of the pool, but the bank increases its revenue by shifting losses to depositors. Prudential regulation can thus have a role in solving this commitment problem and restoring efficiency. Casual evidence cited in Franke and Krahnen (2008) shows that "the allocation of risks in securitization transactions is one of the well guarded secrecies of the industry" and that despite inconsistencies in empirical studies "the observed risk transfer is probably quite different from what theory predicts." The paper concurs with Franke and Krahnen (2007) that "the actual allocation of these tranches to investors in the economy is of particular relevance for bank supervisors."

Another impediment to optimal CRT is that pool performance is difficult to measure. As pointed out by Tirole (2009), an important regulatory issue is whether dynamic management of liquidity has a role to play beyond the usual solvency requirement. The upshot of the model is that, by properly managing liquidity, the trust can reveal the market value of pool performance and remove all uncertainty about the underlying quality of servicing, thus obviating the need to rely on a proprietary quantitative risk model or some expert judgement exercised by bank supervisors. The buffer balance is maintained between size-contingent minima and maxima and meant to be used up in case of need. Drawing down the liquidity position does not leave the buffer exposed to the "repeated" liquidity shock conendrum (Goodhart, 2008). Should a jolt of bad news deplete the liquidity buffer below the minimum required, the pool goes into stochastic liquidation with two options: replenishment by the trust, or takeover by the regulator. Such liquidity management is broadly consistent with the view that information acquisition plays a role in equilibriums with adverse selection when there is uncertainty about the motives for selling assets (Malherbe, 2009). A high liquidity position is capital buffer. 
justified when performance is good, as investors are not wary of the agent's overhoarding liquidity through the securitization of low quality assets. Conversely, a tight liquidity position is justified when performance is poor, as the threat of stochastic liquidation assuages fears about the quality of servicing and dispenses with the need for costly liquidity hoarding.

One last pitfall of CRT is that the retention rate requirements usually taken as the main incentive alignment device in securitization run afoul when banks are compensated with the high coupons paid on the tranches ${ }^{9}$ they hold. Our results imply that banks are not entitled to receive the coupons generated by the protection they extend, lest they were considered as simple arbitrageurs operating in the credit derivatives market. The CDO premium flows waived by banks can be viewed as pre-payment for the contingent support they receive from the trust as a result of their limited liability at the time of liquidation. It resembles a capital insurance scheme, such as the one proposed by Kashyap, Rajan and Stein (2008). When losses begin unfolding capital is automatically supplied by sponsoring banks and the tax is high. Only under liquidation capital is overwhelmingly supplied by the trust and the liquidity tax eventually eschewed.

\section{Related literature}

The paper belongs to the recent and fertile literature on dynamic moral hazard, as illustrated by DeMarzo and Sannikov (2006), DeMarzo and Fishman (2007a, 2007b), Biais et al (2007) or Sannikov (2008). Many papers deal with frequent and infinitesimal risk, but Sannikov (2005) also has Poisson risk. A difference is that jumps are associated with upside cash-flow shocks, which leads to predictable downsizing and qualitatively different results. In Biais et al (2009), moral hazard is about large and infrequent risks. As in our model and unlike in the Brownian case, investors inflict sharp reductions in the agent's continuation utility when losses occur and unpredictable downsizing when performance is poor. Firm size dynamics is different because the agent can expand through investment and follow asymptotically a positive growth trend. In contrast ABS

\footnotetext{
${ }^{9}$ The cashflow "waterfall" implied by actual CDOs usually allocates loan income according to descending priority. Excess interest payments from the mortgage pool are paid to the equity tranche holder provided some conditions, such as the interest coverage or overcollateralization tests, are met. Such payments can arise in principle even when the equity tranche has been used up; cf. Chaplin (2005).
} 
refer to a discrete pool of assets that eventually ceases to exist. Our analysis offers a first description of unpredictable downsizing in a non-stationary context.

The paper is related to several other strands of literature. There is compelling evidence about the importance of servicers in securitization. Ashcraft and Shuermann (2008) discuss the frictions that arise in the atomized setting of securitization and show that the servicer's role is not confined to the collection and remittance of loan payments. These activities have consequences for the performance of loans, with an impact of plus or minus 10 percent on loss according to a Moody's estimate. Piskorski at al (2009) show empirically that securitization induces a foreclosure bias in private subprime mortgages, with delinquent loans having a foreclosure rate between 3.8 and 7 percent lower in absolute terms (18 to 32 percent in relative terms) when held by the bank rather than securitized. This contrasts somewhat with Adelino et al (2009) who find on a smaller sample of the same dataset that servicers do not use direct modifications of contractual terms as a frequent renegotiation tool. Foote et al (2009) also question the importance of contract frictions behind the apparent paradox of low renegotiation. Their focus is on modifications done en masse. Piskorski et al's finding that bank-held delinquent loans are more likely to resume making payments than comparable securitized loans adds credence to the contract friction hypothesis, to the extent that investors ultimately care about the outcome of renegotiation activity. Gan and Mayer (2006) discuss the role of the "special servicer" who is responsible for the borrower work-out and foreclosure functions. They find that when they hold the first-loss piece, special servicers appear to behave more efficiently, with a positive impact on the price of junior tranches. In Cantor and $\mathrm{Hu}$ (2006), the weaker performance of certain types of sponsors is related to their incentives to economize on quality servicing or select risky assets. Pennington-Cross and Ho (2006) examine the heterogeneity of servicers in securitized subprime mortgages and estimate very large increases or decreases in the probability of a loan going to default or prepayment relative to the reference group.

Several papers examine the implications of credit risk transfer (CRT) for banks' incentives to monitor that recent empirical studies document. ${ }^{10}$ They generally find that CRT has negative repercussions on

\footnotetext{
${ }^{10}$ See, for example, Berndt and Gupta (2008), Drucker and Puri (2007), Keys et al. (2008).
} 
monitoring incentives. These results hold against the backdrop of Innes (1990), who shows that under a monotone likelihood ratio property (MLRP) debt financing maximizes the reward for monitoring. A notable exception is Chiesa (2008), who departs from MLRP by assuming that the medium performance of a portfolio must reveal a bank that has monitored in a downturn. Fender \& Mitchell (2008) extend the model in various dimensions to focus on the incidence of different retention mechanisms on banks' incentives to screen borrowers. Here we suggest that the lack of MLRP is not necessary to vindicate CRT. Duffie (2008) uses numerical simulations to show that the issuer has an incentive to reduce dramatically both the fraction retained and the effort level when the cost of monitoring is sufficiently high. The reduction in default intensity through monitoring follows Duffie and Gârleanu (2001) and features a richer set of parameters and controls than in our model. On the other hand, retention is limited to the equity tranche.

Pooling and tranching have been rationalized in the literature, in particular as an incentive for issuers to acquire inside information about asset values prior to sale. Using the security design model of De Marzo and Duffie (1999), DeMarzo (2005) shows that tranching mitigates an adverse selection problem by allocating information-insensitive derivative securities to remote investors while intermediaries' retention of junior tranches signals their superior ability in valuing assets. In a similar vein, Plantin (2004) shows that tranching is optimal when financial institutions differ in their ability to screen collateral and redistribute securities. A paper close to ours is Franke and Krahnen (2006) who argue that, with payoffs indexed to system-wide macroeconomic shocks, intermediaries' retention of tranches should ensure that their risk share increases with the influence they have through monitoring. Interestingly, their results indicate that banks' securitization activity is associated with an increase in their systematic risk, not a reduction, which they interpret as the higher correlation in risk exposures implied by banks reinvesting the proceeds from securitization in new loans with the same properties as those in their initial books.

\section{Conclusion}

While the literature generally considers endogenous liquidation values with exogenously given contracts (Schleifer and Vishny, 1992), here we endogenize contracts with exogenously given liquidation values. We 
find under crude assumptions that bank pay, capital requirements, securitization and liquidity risks should not be regulated separately, each under its own "global framework." Servicers' compensation must be made contingent on past performance. Past performance is revealed to outside investors through transparent liquidity management. Liquidity management in turn is best carried out using credit derivatives as instruments. Finally, the optimal capital requirement determines, up to gains on sale, the size of the liquidity buffer at the time of issuance.

The focus of the paper is on the quality of servicing. The simple message is that diligent servicing may reduce defaults on bank loans just as continuous testing of students reduces the probability of failure. ${ }^{11}$ One caveat is that, as we have stressed in Section 2, the definition of "servicers" does not only encompass the renegotiation of delinquent loans but many other functions such as the broader "administration" of the pool. The organization of servicing is also quite complex, and servicers are not necessarily affiliated with the sponsor. Another, perhaps more important, caveat is that we have taken the existence of contractual frictions as granted. More work is needed to ascertain the claim of the renogotiation-failure theory (Foote et al, 2009), according to which contractual frictions between servicers and investors are to blame for the crisis of the subprime mortgage market in the US.

\footnotetext{
${ }^{11}$ I am indebted to Robert Krainer (U. of Wisconsin) for the analogy.
} 


\section{$7 \quad$ References}

Acharya, Viral and Phillip Schnabl, 2008, "How banks played the leverage game," White Paper in Repairing the US Financial Architecture, NYU Stern School of Business, edited by Viral Acharya and Matthew Richardson.

Adelino, Manuel, Kristopher Gerardi and Paul Willen, 2009, "Why Don’t Lenders Renegotiate More Home Mortgages? Redefaults, Self-Cures and Securitization," NBER Working Paper No. 15159.

Ashcraft, Adam and Til Schuermann, 2008, "Understanding the securitization of subprime mortgage credit," Federal Reserve Bank of New York Staff Reports, no. 318.

Berndt, Antje and Anurag Gupta, 2008, "Moral hazard and adverse selection in the originate-to-distribute model of bank credit." Available at http://papers.ssrn.com/sol3/papers.cfm?abstract_id=1290312.

Biais, Bruno, Thomas Mariotti, Guillaume Plantin and Jean-Charles Rochet, 2007, "Dynamic security design: Convergence to continuous time and asset pricing implications," Review of Economic Studies, 74, 345-390.

Biais, Bruno, Thomas Mariotti, Jean-Charles Rochet and Stéphane Villeneuve, 2010, "Large Risks, Limited Liability and Dynamic Moral Hazard," Econometrica, 78(1), 73-118.

Brémaud, Pierre, 1981, "Point processes and queues: Martingale dynamics," Springer Verlag.

Cantor, Richard and Jian $\mathrm{Hu}, 2007$, "Deal sponsor and credit risk of asset-backed and mortgage-backed securities," Moody's Investors Service, Working Paper.

Chaplin, Geoff, 2005, "Credit Derivatives," Wiley Finance.

Chiesa, Gabriella, 2008, "Optimal credit risk transfer, monitored finance, and banks," Journal of Financial Intermediation, 17, 464-477.

Coval, Joshua, Jakub Jurek and Erik Stafford, 2009, "Economic catastrophe bonds," American Economic Review, 99(3), 628-66.

Dang, Tri Vi, Gary Gorton and Bengt Holmström, 2009, "The Optimality of Debt in Liquidity Provision," notes.

Dell'Ariccia, Giovanni, Deniz Igan and Luc Laeven, 2008, "Credit Booms and Lending Standards: evi- 
dence from the Subprim Mortgage Market," IMF Working Paper, 08/106.

DeMarzo, Peter, 2005, "The pooling and tranching of securities: A model of informed intermediation," Review of Financial Studies, 18, 1-35.

DeMarzo, Peter and Darrell Duffie, 1999, "A liquidity-based model of security design," Econometrica, $67(1), 65-99$.

DeMarzo, Peter and Yuliy Sannikov, 2006, "Optimal security design and dynamic capital structure in a continuous-time agency model," Journal of Finance, 61, 2681-2724.

DeMarzo, Peter and Michael Fishman, 2007a, "Agency and optimal investment dynamics," The Review of Financial Studies, 20, 151-189.

DeMarzo, Peter and Michael Fishman, 2007b, "Optimal long-term financial contracting," The Review of Financial Studies, 20, 2079-2128.

Demyanyk, Yuliya and Otto van Hemert, "Understanding the Subprime Mortgage Crisis," Review of Financial Studies, forthcoming.

Drucker, Steven and Manju Puri, 2007, "On loan sales, loan contracting and lending relationships," BIS Working Papers, No 255.

Federal Register, 2005, 17 CFR Parts 210, 228, "Asset-Backed Securities; Final Rule," Securities aand Exchange Commission.

Duffie, Darrell, 2008, "Innovations in credit risk transfer: Implications for financial stability," BIS Working Papers, No 255.

Duffie, Darrell and Nicolae Gârleanu, 2001, "Risk and valuation of collateralized debt obligations," Financial Analysts Journal, 57(1), 41-62.

Fender, Ingo and Janet Mitchell, 2008, "Incentives and tranche retention in securitisation: A screening model," Working Paper.

Foote, Christopher, Kristopher Gerardi, Lorenz Goette and Paul Willen, 2009, "Reducing Foreclosures," Public Policy Discussion Paper 09-2, Federal Reserve Bank of Boston.

Franke, Günter and Jan Krahnen, 2007, "Default risk sharing between banks and markets: the contri- 
bution of collateralized debt obligations," in The Risks of Financial Institutions, ed. by M. Carey and R. Stulz (NBER book), 603-634.

Franke, Günter and Jan Krahnen, 2008, "The future of securitization," Working Paper. Available at SSRN: http://papers.ssrn.com/sol3/papers.cfm?abstract_id=1284989

Gan, Yingjin and Christopher Mayer, 2006, "Agency conflicts, asset substitution, and securitization," NBER Working Paper No 12359.

Goodhart, Charles, 2008, "Liquidity Risk Management," Banque de France Financial Stability Review, $11,39-44$.

Gorton, Gary and George Pennacchi, 1990, "Financal intermediaries and liquidity creation," Journal of Finance, 45, 49-71.

Hart, Oliver and Luigi Zingales, 2008, " A New Capital Regulation for Large Financial Institutions," CEPR Discussion Paper 7298.

Hellwig, Martin, 2009, "Systemic Rik in the Financial Sector: An Analysis of the Subprime Mortgage Financial Crisis," De Economist, 157, 129-207.

Holmström, Bengt and Jean Tirole, 1998, "Private and public supply of liquidity," Journal of Political Economy, 106(1), 1-40.

Kashyap, Anil, Raghuram Rajan and Jeremy Stein, 2008, "Rethinking Capital Regulation," Working Paper. Available at http://www.kc.frb.org/publicat/sympos/2008/KashyapRajanStein.08.08.08.pdf

International Monetary Fund, 2008, "Containing Systemic Risks and Restoring Financial Soundness, Global Financial Stability Report." Available at http://www.imf.org/External/Pubs/FT/GFSR/2008/02/ index.htm

Innes, Robert, 1990, "Limited liability and incentive contracting with ex-ante action choices, Journal of Economic Theory, 52(1), 45-67.

Karlin, Samuel and Howard Taylor, 1975, "A First Course in Stochastic Processes," Second Edition, Academic Press.

Keys, Benjamin, Tanmoy Mukherjee, Amit Seru and Vikrant Vig, 2008, "Did securitization lead to lax 
screening? Evidence from subprime loans." Available at SSRN: http://papers.ssrn.com/sol3/papers.cfm? abstract_id=1093137.

Laurent, Jean-Paul, Areski Cousin and Jean-David Fermanian, 2008, "Hedging default risks of CDOs in Markovian contagion models." Available at DefaultRisk: http://www.defaultrisk.com/pp_cdo_26.htm.

Malherbe, Frédéric, 2009, "Self-Fulfilling Liquidity Dry-ups," Working Paper, ECARES, Université Libre de Bruxelles.

Mulligan, Casey, 2009, "Means-Tested Mortgage Modification: Homes Saved or Income Destroyed?," Working Paper, University of Chicago. Updates provided on www.panic2008.net.

O'Keefe, John, 2009, "The Effects of Underwriting Practices on Loan Losses: Evidence from the FDIC Survey of Bank Lending Practices," Working Paper, Federal Deposit Insurance Corporation

Pennington-Cross, Anthony and Giang Ho, 2006, "Loan Servicer Heterogeneity and the Termination of Subprime Mortgages," Federal Reserve Bank of St. Louis, Working Paper 24A.

Piskorski, Tomasz, Amit Seru and Vikrant Vig, 2009, "Securitization and Distressed Loan Renegotiation: Evidence from the Subprime Mortgage Crisis," Working Paper.

Plantin, Guillaume, 2004, "Tranching," Working Paper, London School of Economics.

Sannilkov, Yuliy, 2005, "Agency problems, screening and incresing credit lines," Mimeo, University of California, Berkeley.

Sannikov, Yuliy, 2008, "A continuous-time version of the principal-agent problem," Review of Economic Studies, 75, 957-984.

Schleifer, Andrei, and Robert Vishny, 1992, "Liquidation values and debt capacities: A market equilibrium approach," The Journal of Finance, 47(4), 1343-1366.

Tirole, Jean, 2009, "Illiquidity and All Its Friends," Working Paper, Toulouse School of Economics.

Tirole, Jean, "From Pigou to Extended Liability: On the Optimal Taxation of Externalities under Imperfect Financial Markets," Review of Economic Studies, forthcoming. 


\section{Appendix}

\subsection{Pool size analytics}

\subsubsection{Two loans}

With normalized ${ }^{12} w_{2}^{1}(\theta)=b_{1}^{-1} v_{2}(u)$ the ODE specifying investors' continuation utility when $i=2$ becomes

$$
\left(\frac{b_{2}}{b_{1}}\left(\lambda_{2}+r\right)+r \theta\right) \dot{w}_{2}^{1}+\lambda_{2} \frac{b_{2}}{b_{1}} \frac{\mu \epsilon}{B}-\lambda_{2}\left(w_{2}^{1}-\theta \bar{w}_{1}\right)=0
$$

the solution of which can be written as

$$
w_{2}^{1}(\theta)=B_{2}^{1}+A_{2}^{1} \theta-C_{2}^{1} \frac{\Lambda_{2}^{1}}{\lambda_{2}}\left(\frac{\Lambda_{2}^{1}+r \theta}{\Lambda_{2}^{1}}\right)^{\lambda_{2} / r}
$$

where parameters (also used in sections below) are as follows

\begin{tabular}{|c|c|c|c|c|}
\hline Variable & $\Lambda_{i}^{j}$ & $A_{i}^{j}$ & $B_{i}^{j}$ & $y_{i}$ \\
\hline Definition & $\frac{b_{i-j+1}}{b_{i-j}}\left(\Lambda_{i}^{j-1}+r\right)$ & $\frac{\lambda_{i}}{\lambda_{i}-r} A_{i-1}^{j-1}$ & $\sum_{k=0}^{j-1} \frac{b_{i-k}}{b_{i-j}} \frac{\mu \epsilon}{B}+A_{i-k}^{j-k} \frac{\Lambda_{i-k}^{j-k}}{\lambda_{i-k}}$ & $\left(\frac{\Lambda_{i}^{1}}{\Lambda_{i}^{1}+r}\right)^{\lambda_{i} / r-1}$ \\
\hline Remarks & $\Lambda_{i}^{0}=\lambda_{i}$ & $A_{i}^{0}=\frac{b_{i-1}}{b_{i}} \bar{w}_{i}$ & $B_{i}^{1}=\frac{b_{i}}{b_{i-1}} \frac{\mu \epsilon}{B}+A_{i}^{1} \frac{\Lambda_{i}^{1}}{\lambda_{i}}$ & $\frac{\mu \epsilon}{B}>\frac{\lambda_{i}-r}{\lambda_{i}} \frac{y_{i}}{1-y_{i}}$ \\
\hline
\end{tabular}

with $i \geq 2, j<i$ and the convention $b_{0}=b_{1}$.

The free parameter $C_{2}^{1}$ is determined by the boundary condition $\dot{w}_{2}(1)=-1$, yielding $C_{2}^{1}=\left(1+A_{2}^{1}\right) y_{2}$. When the target $u=b_{2}+b_{1}$ is reached, the servicer receives a continuous fee of $\delta_{2}=r\left(b_{2}+b_{1}\right)+2 B / \epsilon$ until either of the two loans defaults. Her continuation utility then jumps to $b_{1}$.

A technical condition is needed to ensure that $w_{2}^{1}$ is originally increasing in the agent's continuation utility.

Assumption 3 There exists $k$ such that $k \leq \alpha_{i} / \alpha_{i-1}<1$ and $\bar{w}_{1} \equiv \bar{v}_{1} / b_{1}=\mu \epsilon / B-\left(\lambda_{1}+r\right) / \lambda_{1}>$ $1 / \ln (1+k / 2)$.

\footnotetext{
${ }^{12}$ The notation $w_{i}^{j}(\theta)$ refers to a normalized solution with $i$ loans over the $j$ th interval $\left[b_{i}+\cdots+b_{i-(j-1)}, b_{i}+\cdots+b_{i-j}\right]$. It is defined as $w_{i}^{j}(\theta)=v_{i}(u) / b_{i-j}$ where $\theta$ is the position of $u$ in that interval.
} 
This requires that the loan revenue be all the higher in proportion of rents, the higher the maximum increase in individual risk $\alpha_{i-1} / \alpha_{i}=1 / k$. The condition implies that $A_{2}^{1}=\lambda_{2} /\left(\lambda_{2}-r\right) \bar{w}_{1}>y_{2} /\left(1-y_{2}\right)$. Indeed, $y_{2}=\left(\Lambda_{2}^{1} /\left(\Lambda_{2}^{1}+r\right)\right)^{\lambda_{2} / r-1}$ and $\Lambda_{2}^{1}=\left(b_{2} / b_{1}\right)\left(\lambda_{2}+r\right)$ imply

$$
y_{2}=\left(\frac{x+1}{x+1+b_{1} / b_{2}}\right)^{x-1} \leq\left(\frac{x+1}{x+1+k}\right)^{x-1}
$$

where $x=\lambda_{2} / r \geq 1$, so that

$$
\begin{aligned}
\frac{y_{2}}{1-y_{2}} \frac{\lambda_{2}-r}{\lambda_{2}} & \leq \frac{x-1}{x} \frac{\left(\frac{x+1}{x+1+k}\right)^{x-1}}{1-\left(\frac{x+1}{x+1+k}\right)^{x-1}} \\
& \leq-\frac{1}{\ln \frac{2}{2+k}}<\bar{w}_{1}
\end{aligned}
$$

as desired. Hence $C_{2}^{1}=\left(1+A_{2}^{1}\right) y_{2}<A_{2}^{1}$ and $\dot{w}_{2}^{1}(0)=A_{2}^{1}-C_{2}^{1}$ is positive. Moreover,

$$
\bar{w}_{2} \equiv w_{2}^{1}(0)=\frac{b_{2}}{b_{1}} \frac{\mu \epsilon}{B}+\frac{\Lambda_{2}^{l}}{\lambda_{2}}\left(A_{2}^{1}-C_{2}^{1}\right)>\frac{b_{2}}{b_{1}} \frac{\mu \epsilon}{B}
$$

a result needed just below.

\subsubsection{Three loans}

In the stochastic liquidation interval $\left[b_{3}, b_{3}+b_{2}\right]$ investors' normalized continuation utility is solved as before as

$$
w_{3}^{1}(\theta)=B_{3}^{1}+A_{3}^{1} \theta-C_{3}^{1} \frac{\Lambda_{3}^{1}}{\lambda_{3}}\left(\frac{\Lambda_{3}^{1}+r \theta}{\Lambda_{3}^{1}}\right)^{\lambda_{3} / r} .
$$

for some $C_{3}^{1}$. Anticipating somewhat one can show again that investors' utility starts increasing. Before the target is reached one must have $\dot{w}_{3}^{1}(1)>-1$ or equivalently $C_{3}^{1}<\left(1+A_{3}^{1}\right) y_{3}$. But we have just seen above that $\left(\lambda_{3}-r\right) / \lambda_{3} A_{3}^{1}=b_{1} / b_{2} \bar{w}_{2}>\mu \epsilon / B$ and, using the same logic as in the two-loan case under Assumption $3, \mu \epsilon / B>\left(\lambda_{3}-r\right) / \lambda_{3} y_{3} /\left(1-y_{3}\right)$. It follows that $\left(1+A_{3}^{1}\right) y_{3}<A_{3}^{1}$ and $\dot{w}_{3}^{1}(0)=A_{3}^{1}-C_{3}^{1}>0$. 
Moreover

$$
\bar{w}_{3} \equiv w_{3}^{1}(0)=\frac{b_{3}}{b_{2}} \frac{\mu \epsilon}{B}+\frac{\Lambda_{3}^{1}}{\lambda_{3}}\left(A_{3}^{1}-C_{3}^{1}\right)>\frac{b_{3}}{b_{2}} \frac{\mu \epsilon}{B}
$$

a property preserved by induction across all stochastic liquidation intervals of higher order states.

The servicer's position in the second interval $\left[b_{3}+b_{2}, b_{3}+b_{2}+b_{1}\right], \theta=\left(u_{3}-b_{3}-b_{2}\right) / b_{1}$, is the probability of survival given default that the pool faces after a loss. The solution is

$$
\begin{aligned}
w_{3}^{2}(\theta) & =B_{3}^{2}+A_{3}^{2} \theta+\phi_{3}^{2}(\theta)-C_{3}^{2} \frac{\Lambda_{3}^{2}}{\lambda_{3}}\left(\frac{\Lambda_{3}^{2}+r \theta}{\Lambda_{3}^{2}}\right)^{\lambda_{3} / r}, \\
\left(\Lambda_{i}^{j}+r \theta\right) \dot{\phi}_{i}^{j}(\theta) & =\lambda_{i}\left(\phi_{i}^{j}(\theta)-w_{i-1}^{j-1}(\theta)+B_{i-1}^{j-1}+A_{i-1}^{j-1} \theta\right), \quad \phi_{i}^{j}(0)=0 .
\end{aligned}
$$

The pasting condition

$$
\dot{w}_{3}^{1}(1)=\dot{w}_{3}^{2}(0) \Longleftrightarrow A_{3}^{1}-C_{3}^{1} / y_{3}=A_{3}^{2}-C_{3}^{2}+\dot{\phi}_{3}^{2}(0)
$$

specifies $C_{3}^{1}$ as a function of $C_{3}^{2}$. The differential equations with lags defining the optimal plan have solutions that are continuously differentiable. Pasting derivatives ensures that levels adjust.

Let $\bar{\theta}_{3}$ be the upper boundary of the probation interval. If $\bar{\theta}_{3} \in(0,1)$, it solves the system

$$
\begin{aligned}
& \dot{w}_{3}^{2}(\theta)=-1 \\
& \ddot{w}_{3}^{2}(\theta)=0 .
\end{aligned}
$$

Differentiating the ODE defining $\phi_{3}^{2}$ to eliminate $\ddot{\phi}_{3}^{2}$, one finds after some substitutions that the critical level $\bar{\theta}_{3}$ satisfies

$$
1+\dot{w}_{2}^{1}(\theta)=\frac{r}{\lambda_{3}}
$$

By construction the slope of the objective function declines to -1 until $\theta=1$ so $\bar{\theta}_{3}$ is certainly less than one. Since $\dot{w}_{2}^{1}(0)$ is positive $\bar{\theta}_{3}$ is away from zero. All parameters are then recovered from the boundary condition $1+\dot{w}_{3}^{2}\left(\bar{\theta}_{3}\right)=0$. 


\subsubsection{Four loans}

With $i=4$ the normalized solution in the second interval $\left[b_{4}+b_{3}, b_{4}+b_{3}+b_{2}\right]$ is

$$
w_{4}^{2}(\theta)=B_{4}^{2}+A_{4}^{2} \theta+\phi_{4}^{2}(\theta)-C_{4}^{2} \frac{\Lambda_{4}^{p}}{\lambda_{4}}\left(\frac{\Lambda_{4}^{p}+r \theta}{\Lambda_{4}^{p}}\right)^{\lambda_{4} / r} .
$$

If probation is contained in this second interval, let $\bar{\theta}_{4} \in(0,1)$ be the upper boundary. It is again determined by the pasting conditions $\dot{w}_{4}^{2}=-1$ and $\ddot{w}_{4}^{2}=0$ leading to

$$
1+\dot{w}_{3}^{1}(\theta)=\frac{r}{\lambda_{4}}
$$

The social value of performance is $1+\dot{v}_{3}\left(u-b_{4}\right)$ one step ahead. The current relative cost of performance is $r / \lambda_{4}$. Whether or not $\bar{\theta}_{4}<1$ depends on which interval one step ahead has a social value of performance equal to the current cost. If this happens when $v_{3}(u)=b_{2} w_{3}^{1}(\theta)$, the stochastic liquidation interval of regime 3 , condition (4) is met in the second interval of regime 4 and yields the target $\gamma_{4}=b_{4}+b_{3}+\bar{\theta}_{4} b_{2}$. If this happens when $v_{3}(u)=b_{1} w_{3}^{2}(\theta)$, the probation interval of regime 3 , condition (4) cannot be met because the social value of performance is still high relative to its cost at $b_{3}+b_{2}$. But then $1+\dot{v}_{3}\left(b_{3}+b_{2}\right)>r / \lambda_{4}$ and the smooth pasting condition for the boundary $\bar{\theta}_{4}$ in the third interval $\left[b_{4}+b_{3}+b_{2}, b_{4}+b_{3}+b_{2}+b_{1}\right]$ reads

$$
1+\dot{w}_{3}^{2}(\theta)=\frac{r}{\lambda_{4}}
$$

and yields the target $\gamma_{4}=b_{4}+b_{3}+b_{2}+\bar{\theta}_{4} b_{1}$.

In either case, the remaining unknown parameters can be recovered by continuity from the slope of investors' utility $v_{4}$, starting from the outermost interval with $\dot{v}_{4}\left(\gamma_{4}\right)=-1$ and working back to the left. 


\section{Proof of Proposition 3}

From the servicer's integrated promise-keeping constraint (2) along the optimal path, we know that for all $t \leq \tau$

$$
u_{t}=u^{*}+\int_{0}^{t}\left(r u_{s}+\frac{B i}{\epsilon}\right) 1_{\left\{u_{s}<\gamma_{i}\right\}} d s-\int_{0}^{t} b_{i} \wedge\left(u-b_{i-1}\right) \sum_{j} d N_{s}^{j}-\int_{0}^{t} b_{i-1} d M_{s},
$$

where $i=I-\sum_{j} N_{t}^{j}$. By construction, the protection sold by the sponsor is

$$
P\left(N_{t}\right)=\int_{0}^{t} b_{i} \sum_{j} d N_{s}^{j}+\left(\sum_{j<i} b_{j}\right) M_{t \wedge \tau}
$$

since at $t=\tau$ the default count jumps from $\sum_{j} N_{\tau}^{j}$ to $I$. Thus

$$
u_{t}+P\left(N_{t}\right)=u^{*}+\int_{0}^{t}\left(r u_{s}+\frac{B i}{\epsilon}\right) 1_{\left\{u_{s}<\gamma_{i}\right\}} d s+\xi_{t}+\left(\sum_{j<i} b_{j}\right) M_{t \wedge \tau}
$$

where the martingale

$$
\xi_{t}=\int_{0}^{t}\left[b_{i}+b_{i-1}-u\right]^{+} \sum_{j} d N_{s}^{j}-\int_{0}^{t} b_{i-1} d M_{s}
$$

is the trust's cumulated cost resulting from intervention on the buffer during stochastic liquidation episodes. With probability $\theta$, the pool is maintained and the trust pays the shortfall $\Delta \xi=b_{i}+b_{i-1}-u$. With probability $1-\theta$ the pool is liquidated and the trust wins the residual balance $-\Delta \xi=u-b_{i}$. Evaluating (5) at $t=\tau$ with $u_{\tau}=0$ and $N_{\tau}=I$, we get

$$
\sum_{j \leq I} b_{j}=u^{*}+\int_{0}^{\tau}\left(r u_{s}+\frac{B i}{\epsilon}\right) 1_{\left\{u_{s}<\gamma_{i}\right\}} d s+\xi_{\tau}+\sum_{j<i^{*}} b_{j}
$$

where $i^{*}=I-\sum_{j} N_{\tau}^{j}$ is the pool size at liquidation. 
The sponsor maximizes its profit since by construction

$$
\begin{aligned}
u^{*} & =E \int_{0}^{\tau} e^{-r t}\left(r \gamma_{i}+\frac{B i}{\epsilon}\right) 1_{\left\{u_{t}=\gamma_{i}\right\}} d t \\
& =E \int_{0}^{\tau} e^{-r t} \delta_{t} d t .
\end{aligned}
$$

The trust's costs and benefits in the course of the relationship are as follows

\begin{tabular}{|c|c|c|}
\hline & Cost & Benefit \\
\hline$t=0$ & $u^{*}+v^{*}$ & - \\
\hline$(t, t+d t)$ & $\left(r u_{t}+\frac{B i}{\epsilon}\right) 1_{\left\{u_{t}<\gamma_{i}\right\}}$ & $i \mu-\delta_{t}+\Sigma_{t}$ \\
\hline Liquidation & $\xi_{\tau}+\sum_{j<i^{*}} b_{j}$ & - \\
\hline
\end{tabular}

where $\Sigma_{t}$ is the premium flow from the CDO tranches. From (6), the overall cost is deterministic and equal to $v^{*}+\sum_{j \leq I} b_{j}$. But

$$
\begin{aligned}
v^{*} & =E \int_{0}^{\tau}\left(i \mu-\delta_{t}\right) d t \\
\sum_{j \leq I} b_{j} & =E \int_{0}^{\tau} \Sigma_{t} d t,
\end{aligned}
$$

the first equality by design, the second by arbitrage since at date $\tau$, the pool is liquidated and $N_{\tau}=I$. The trust breaks even. 